\title{
Effectiveness of the Alternative Learning System Informal Education Project and the Transfer of Life Skills among ALS Teachers: A Case Study
}

\author{
Manuel E. Caingcoy'), Juliet L. Pacursa ${ }^{2)}$, Ma. Isidora W. Adajar ${ }^{3)}$ \\ 1), 2), 3) College of Education, Bukidnon State University, Malaybalay City, Philippines \\ Corresponding Author: caingcoymanuel@gmail.com, ORCID: 0000-0002-3862-1561
}

\begin{abstract}
Alternative Learning System (ALS) has been adopted in Philippine basic education, yet there is no academic institution in the region that prepares ALS teachers in teaching life skills. ALS teachers graduated from different programs of teacher education for formal education. In response, an extension project was conceptualized and implemented to enhance the teaching capacity and effectiveness of ALS teachers. A case study was conducted to evaluate the effectiveness of the project. It explored the transfer of life skills among ALS teachers. Data were collected from multiple sources. Interview and written responses, and feedbacks were analyzed using thematic narrative analysis. Other data were analyzed using document and descriptive analyses. The project had achieved its objectives and was rated best by participants. These indicate that the project was implemented effectively and successfully. ALS teachers have acquired life skills and transferred them to others. Thus, the project has made a difference in the lives of these teachers.
\end{abstract}

Keywords: Effectiveness, alternative learning system-informal education, transfer of life skills

\section{Introduction}

Studying the life skills become an important debate in formal and informal education. It became a trend, particularly in non-formal education. Previous studies contribute to enriching the body of knowledge that help educators, advocates, policy-makers, project developers, and implementers of non-formal education understand the problems that relate life skills. With sufficient knowledge, practitioners and curriculum developers can use empirical evidence. However, there was a limited body of knowledge on life skills among implementers of informal education. Yet, they are supposed to be well-trained individuals who can ensure the effective delivery of informal education in the Department of Education.

Life skills include decision-making, community living, personal awareness, and management (AGI, 2013). They enable to translate knowledge, attitudes, and values into actual abilities (Vihar, n.d.). Prajapati et al. (2017) clustered them into thinking, social and emotional skills. Life skills are important competencies that every learner should acquire. They can make learners more useful and productive individuals in society. Adolescent Girls Initiatives of World Bank (2013) explained what these skills are, why they matter, and how they can be taught in the field. As posited, life skills are a broad set of social and behavioral skills or sometimes called as soft or non-cognitive skills that allow individuals to deal with everyday demands in life (AGI-World Bank, 2013). A previous study recognized life skills education to bridge the gap between basic functioning and capabilities. It strengthens the ability of an individual to meet the needs and demands of the present society, and helps in dealing with issues in a practical manner" (Prajapati et al., 2017, p. 1). In Singapore, teachers have identified a wide range of life skills and also skills relating to character building, household, livelihood, and survival skills (Tan, 2018). However, one study reported the insufficiency of life skills in education. This insufficiency was attributed to several factors that include a strong emphasis on academic excellence, success and achievement, and non-responsive government policies (Shek et al., 
2020). Secretary Leonor Briones directed her agency to intensify and enhance the Alternative Learning System (Department of Education, 2019).

Alternative Learning System (ALS) has been integrated into the Department of Education in the Philippines as a parallel program to formal basic education. However, the education sector has been facing challenges in the implementation of ALS across regions because the implementers were graduates of Secondary, Elementary, and Early Childhood Education. Competencies acquired in college do not match with the competencies of the Alternative Learning System. In Northern Mindanao areas, there is no academic institution that offers such program. And so, implementers within the region need further training to make them aligned with and congruent to the services they are rendering. In 2016, CHED has come up with a draft of the Policies, Standards, and Guidelines (PSGs) for the Bachelor of Alternative Learning System program. Through a memorandum order (CMO no. 83, series of 2017), CHED released these PSGs to higher education institutions so that the degree program can have a legal basis. In the third quarter of 2020, the House of Representatives approved at the third and final reading of House Bill No. 6910 or the Alternative Learning System Act (Philippine News Agency, 2020). So far, there is no response and development from the Philippine Senate. The late crafting of these important policies had made HEIs reluctant to offer ALS as a degree program and yet it's been a long time DepEd has been deploying implementers in the field whose backgrounds and degrees are not really for alternative learning system.

The valuation of life skills program or project is essential in order to develop the evidence base and substantiate this claim (D'Arcy, 2014). The Bukidnon State University- College of Education has conceptualized and implemented the ALS InFed project to respond to the longrunning challenges met by the ALS implementers in educating the young and adults in preparing them for life and in making them lifelong learners. The project is dubbed "Capacitating the ALS InFed Teachers in Teaching Life-Skills Education." The project was launched in November 2018. This was to bridge the gap between the competencies of ALS implementers and the competencies or skills needed by ALS learners. In 2019, it has successfully implemented most of the modules in phase 1 . This paper intends to evaluate the effectiveness of the project and explore the transfer of skills among ALS teachers. This was done to draw vital information for decision-making and re-planning of phase 2. Also, this paper reports how the project changed the lives of the participants and how they have applied the skills in the field. Moreover, the results of this paper can be bases on offering an Alternative Learning System degree program, diploma, or short course in the future.

\section{Research Method}

This paper utilized a case study in which the evaluation gathered data from multiple sources such as the interview, written responses of open-ended questions, reports, accomplished feedback forms, and photos. The interview was administered to four ALS InFed teachers via google meet. Questions used in the interview were also sent to participants to triangulate the data. The interview and written responses were analyzed using a thematic narrative analysis of Riessman (2008). Annual reports, accomplished feedback forms, photos, and the evaluation records were revisited and analyzed to find out if the project has met the expectations of the participants and if they were satisfied with the trainings. Every session was evaluated using a scale of 1 (poor) to 5 (best). Quantitative data were analyzed using descriptive statistics. Moreover, it analyzed feedback responses and photos taken in the actual training and transfer of skills. 


\subsection{The Project}

The project (Capacitating the ALS InFed Teachers in Teaching Life-Skills Education) was designed and implemented to upgrade ALS teachers with various life skills, strategies, and methods to effectively deliver informal education. It was carried out by conducting series and modular seminar-workshops. It covered the digital layout and multi-media production which covers the basic lay outing, digitizing 2D designs, digital lay outing and design, and multimedia development (Module1); principles of flower arrangement, designs of flower arrangement, tips of prolonging freshness of flowers, topiary and Ikebana making, corsage and bouquet making, and presidential table flower arrangement (module 2); balloon arts that includes the principles of balloon arrangement, techniques on balloon blowing, and designs of balloon arrangement (module 3); arts and crafts highlights different kinds recyclable materials, possible uses of recyclable materials, different crafts using recyclable materials (module 4); basic cookery and bread pastries that focus on the principles of baking, major and minor ingredients in baking, different types of baked products, equipment and utensils in baking, and processing of different baked products (module 5); food processing that trains participants on the principles of food preservation, methods and techniques of food preservation, market forms of fish and meat, and processing of different meat products (module 6); and meal management that covers the goals and procedure of meal management, types of table setting, and table skirting (module 7). Specifically, the project aimed to enhance their teaching skills, conduct lectures/seminars/training on the life skills, and develop a learning package that will cater to the needs of the target clientele (Bukidnon State University, 2018).

\section{Findings and Discussions}

\subsection{Effectiveness of the Project}

After months of implementation, the project was evaluated if it achieves its general and specific objectives. The effectiveness of the project means meeting the expectations of the participants in the series of training conducted. These expectations are the set of criteria employed in the evaluation conducted at the end of every session. Also, the effectiveness entails meeting the project objectives. So far, the project implemented 17 topics from modules 1-5. The utilization and content of the training had the highest rating of 4.99. For the former, the participants have seen the opportunity of applying a product or technology after they would undergo the training. For the latter, they recognized the training and the contents to address the community needs, the ALS teachers and learners. In both criteria, the rating indicates best. This implies that the project was best in terms of the content shared by the resource persons and the opportunity for them to use a product or technology after the trainings. Similarly, Dupuy et al. (2018) reported that $95 \%$ of the beneficiaries assessed the life skills program as "good" and "very good." Criteria of the said evaluation include relevance to the current needs, practical usefulness, and general benefits of the trainings. The use of instructional materials and the participation or cooperation among the participants, respectively, had the same rating of 4.97 still evaluated as best. This would suggest that resource persons were using their instructional materials and the participants were actively involved in the process of acquiring the skills. This is expected because the project was more on workshops.

The "objectives" were the third highest-rated criterion. Among the nine criteria, practicality has the least rating but still, it was rated best. Practicality signifies the usefulness of the training to the community. Therefore, this project is practically useful and enabling. All other criteria were rated by the participants include the timeliness, relevance, quality, and accuracy of the training 
to solve a community problem. All of these got the same descriptive rating - best. This means the objectives of every module had been responsive to address their needs of ALS InFed teachers. At this point, it is safe to claim that the ALS InFed project was effective since it achieved what it intends to achieve.

Table 1. Frequency and Percentage Distribution of Trainees in Different Topics/Modules

Modules/Topics

Trainees

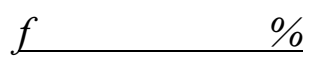

M1.1- Digital Layout and Multi-Media Production

M1.2- Introduction to Basic Lay-Outing

M1.3- Digital Lay-Outing using Photoshop (session 1)

M1.3- Digital Lay-Outing using Photoshop (session 2)

M1.4- Multi-Media Production

M2.1- Flower Arrangement-Principles of Flower

Arrangement \& Designs

M2.2- Flower Arrangement-Tips of Prolonging

M3 - Balloon Arts with Flower Arrangement

M4.1- Arts \& Crafts - Introduction \& Orientation

M4.2- Arts \& Crafts -Using Recyclable Materials

M4.3- Arts \& Crafts - Backdrop Lay-Outing \& Letter Cutting

M4.4- Arts \& Crafts - Creatures \& Organizers

M4.5- Arts \& Crafts - Using Crayons \& Box Organizer Making

M5.1-Basic Cookery: Principles of Baking and Major/Minor Ingredients

M5.2-Basic Cookery and Baking Different Products (1)

Table 1 presents the number of trainees who received the series of training in the ALS InFed project. During the launching, the Malaybalay City Division endorsed 50 teachers for the training representing the 10 districts. However, the actual participants vary for every scheduled training. Notice that the total trainees served in the project have reached 424 which was 49.88 per cent of the expected number of trainees ( 850 trainees) at the end of implementing 17 topics. 
This means not all of them were consistently attending the sessions. This concern has to be communicated to the division office for appropriate actions. These individuals may have reasonable circumstances that's why they did not attend frequently. One of these would be the conflict of schedules. Although, the training was pre-scheduled, yet they may have other very important activities to attend to. That's why the appropriate office and authorities have to verify their circumstances and take appropriate action to concerned teachers. Despite its effective implementation, the project has met a challenge- the attendance of participants. This would

\subsection{Transfer of Skills to learners}

The main responsibility of training learners on life skills lies in every ALS teacher. It was revealed that teachers hold high regard for life skills. Teachers have identified a wide range of life skills that relate to character building, household, livelihood, and survival skills (Tan, 2018). In this project, the first objective was to enhance the teaching skills of the ALS Teachers. This implies a long-term change in teachers after a series of training. The succeeding section analyzes whether or not the project has met its desired result. The data from the interviews, open-ended questions, photo documentation, and accomplished feedback forms were used to draw significant evidence. One of the open-ended questions asked if they acquired the skills from the series of training. The very essence of the question was to trace if they have truly acquired the life skills expected of them. Indeed, the narratives indicate they acquired the skills:

Edtech, Balloon Art, Flower arrangement, Backdrop, cooking; Baking and pastries, balloon decorating, flower arrangement, basic editing, and letter cutting; Basic Editing, letter cutting, backdrop design, recyclable organizer; Filler baking and pastries, balloon decorating, and flower arrangement.

During need assessment or conceptualization phase, these teachers acknowledged their limitations in teaching ALS students. These teachers considered the series of training very vital in playing their roles as mobile teachers. The skills they acquired can bring a significant improvement in their work. Some of them say:

Most of the trainings are very essential for me because I [was] able to apply it in our personal needs as a Mobile teacher; The series of trainings are very useful and important for me as an ALS Mobile Teacher because I was able to apply [them] in different ways when those are needed in my teaching.

In one of the sessions, the implementers have distributed the feedback forms to participants. This was to get additional information for monitoring and re-planning purposes. In this form, a set of questions elicited responses as feedbacks. It was asked: Does the extension project of BukSU help you? If yes, in what way or ways does it help you? One hundred per cent had responded "yes." When this question was asked, it was during the training on art and crafts. The responses to the second question are presented below to support the emerging themes. The themes that emerged include capability and creativity, activities and programs, and expenditure and livelihood. Capability and creativity refer to the acquired skills in arts and crafts. They become more capable, especially in making backdrop and tarpaulin, cutting letters and numbers, and combining colors creatively and correctly based on some principles. Accordingly, these skills are useful in teaching ALS students. The training itself stimulated their creativity and innovative skills. Here are some of their feedbacks:

It added to my capability. I can use this for my teaching with my ALS students (FF5); It is a great advantage on my part I was able to make a backdrop (FF7); We 
can now share it with others (FF2); It enables us to combine colors and cut letters. It can greatly help us teachers (FF3); It would greatly help us make creative letters and numbers (FF10). It is useful and it makes us creative in making a backdrop (FF13); It helps us improve and grow in knowledge in cutting letters, the basics in colors and harmony, and most especially it improves our creativity (FF14); It added to my knowledge of making a backdrop (FF16); This is a big help for us to develop the talents of our students (FF18).

From responses, a theme-activities, and programs was derived. ALS teachers find the relevance of the skills they acquired to their work. In verbatim, they said:

This would help ALS during programs, especially schools that are far from the city (FF8); It can help us in different activities of ALS (FF9); It would help ALS in its activities (P6). We can now properly cut letters and it helps us, especially during school activities (FF2); We can make a backdrop for school activities (FF1); It allows us to cut letters for a backdrop (FF12). The training is useful especially there are a lot of activities in school (FF14); It would help me during school programs (FF15); In terms of school activities, it helps a lot (FF18).

The third theme was on expenses and livelihood. This has something to do with the economic value of the training. They said they are no longer hiring nor looking for individuals who will do the decoration, make a tarpaulin, and a backdrop during school programs and activities. Also, they saved and lessen the expenditures. Some of them recognized the value and potentials of their skills for livelihood or additional sources of income. The narratives below support this theme.

We won't look for artists outside our organization to do the work for us. We cannot spend on their talent pay (FF6); I wouldn't ask and depend on others or pay them to do it for me. I could save money (FF7); It would also help us earn a living (FF10); I can help students by providing them a livelihood (FF4); It helps save money in making a tarpaulin (FF12); We need not hire in decorating and making a backdrop (FF15); It can be a source of income (FF18).
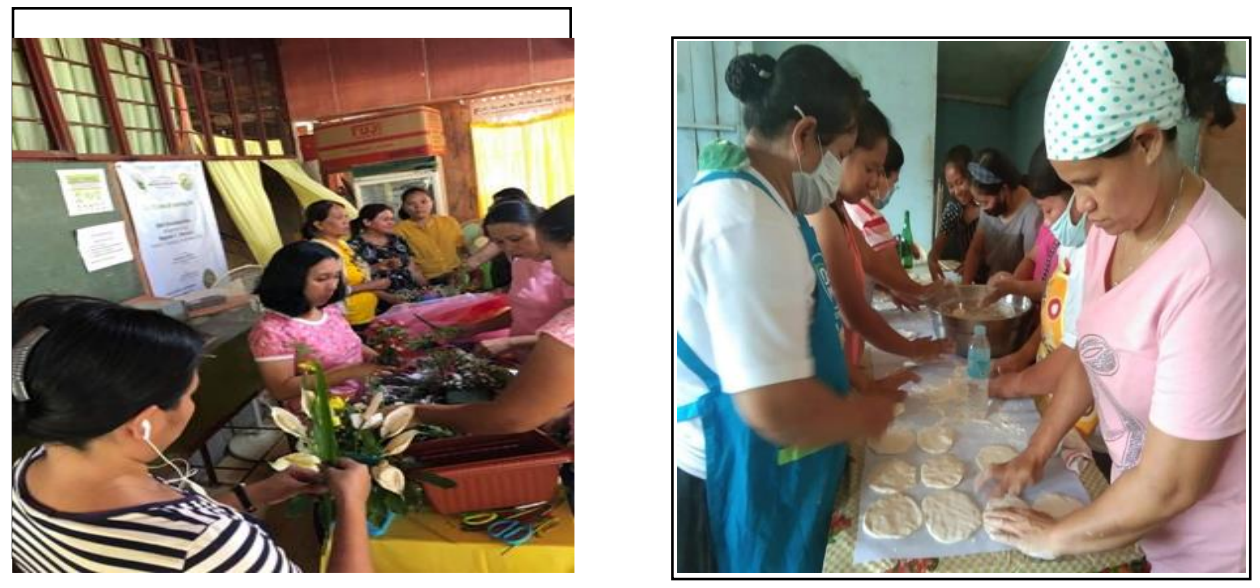
Figure 1: Flower Arrangement

Figure 2: Cookery and Baking

Life skills enable teachers to translate knowledge, attitudes, and values into actual abilities (Vihar, n.d.). In the photos below, the ALS InFed teachers were in action during the flower arrangement, baking, and pastry workshops. They have learned and practiced life skills. Once the facilitators have done demonstrating the skills, ALS teachers were given time to acquire the same skills by producing outputs at the end of every session. As has been argued that in all contexts, the actual utilization of skill must be put into practice for an individual to truly grasp the concept (Cassidy et al., 2018). These authors emphasize the realistic implementation of the project to ensure the acquisition of life skills.

The ALS InFed teachers may have possessed some of the life skills before the series of training, while some of them may not have acquired them in previous in-service training. For the third open-ended question, they were asked if the series of training have made them more effective and capable of teaching life skills. This question was anchored on the main objective of the project that is to enhance the life skills of ALS InFed teachers. Though it was a self-evaluation, their responses are valuable information for the implementers.

It [training] gives me more confidence that I can share more knowledge and skills in which my learners can gain life-long skills; I learned new skills and enhanced my prior learnings of some training that [are] very applicable in my work; The ICT helped me and [I] found an easy way to prepare and deliver my lesson to them. It lessens my time and money in preparing visual aids; Before I lack different skills, that is why I cannot teach them. And now I can teach them what I've learned.

One of them has articulated the progress in herself. Figuratively, she compared the past and the time after she acquired the life skills. She likened herself to a delicious cake. This was an admittance that her life skills were enhanced. One vital information this teacher has voiced out was the intent to become a nationally certified trainer in life skills so that she could also certify the students.

It seems like I am a half- baked cake.... I have prior knowledge of some of the training skills. But with the extension project of BUKSU, I [was] able to acquire new skills and enhance the existing learnings; I do hope that I will be given a certificate on the training that I had so that I could also certify or give certificates to my learners which is very helpful for their employment specifically for those who can't continue higher education; Now, I can proudly say that I am a delicious cake with eye captivating icing.

With the narratives above, it is evident that the project has enhanced ALS teachers' teaching effectiveness and capability. This improvement may have a ripple effect on their learners. Somehow, this supports the previous evidence that students got more interested in learning, come to school more regularly, and find themselves relevant to the community.

\subsection{Transfer of Life Skills to Learners, Families and Community}

"Integrating life skill training through education will help youth to overcome such difficulties in life" (Prajapati et al., 2017, p. 1). A study recognized that "life skills education bridges the gap between basic functioning and capabilities. It strengthens the ability of an individual to meet the needs and demands of the present society, and helps in dealing with issues in a practical manner" (Prajapati et al., 2017, p. 1). The second open-ended question asked was on how they apply the acquired life skills in their respective stations. The series of training and the 
experiences of the participants would become meaningful when they find the relevance of the acquired skills in their current work. The narratives and photos below show how these skills were directly transferred to ALS students. The following narratives are indicative of skills transfer. Thus, ALS teachers have applied what they learned and acquired from the series of trainings.

I shared my acquired skills in balloon art and flower arrangement to my learners on our 1-day ALS InfEd skills training; With the training that I had been through given by BUKSU, I was able to channel it to my ALS learners during our InFEd sessions; We have the actual demonstration and application of skills; Pictures and videos will support that the learners were able to gain the skills conducted; I apply the skills in my teaching by integrating them into my discussion; I used slide show presentations and encoded reports and worksheets of the learners using a computer. Moreover, I taught the learners how to cook palitaw, empanada, and puto cheese.

As a result of knowledge and skills transfer, there were changes in learners after they acquired and developed life skills through ALS teachers. This was true when the learners found the meaning and the usefulness of enhanced life skills and apply them in their schooling, especially in accomplishing academic tasks. Also, learners had become more eager to acquire life skills. As a result, they attend classes more frequently than before. The participants narrate:

They are more confident and also eager to learn more lifelong learning skills; The positive changes happened to my learners upon learning the different skills; The interest of the ALS learners in attending our class sessions increased which is evident in our class attendance; The skills they acquired from me for example ICT -they used it in encoding their projects, research, and learning online; It encourages the learners to pursue their learning because they feel interested and they don't feel bored; Other skills help me encourage them to stay and pursue their studies because it helps develop their knowledge and good values.

World Bank (2014) calls for cooperation that "together we can make a difference in the lives of youth and help them to become productive and engaged members of their families, communities, and countries (p. 49). Yadav et al. (2017) added that "developing different life skills abilities among adolescent students require planning, patients and collective efforts of teachers, parents and school managements" (p. 12). Sobel (2004), advocated for "hands-on, real-world learning experiences... help students develop stronger ties to their community, enhance students' appreciation for the natural world, and create a heightened commitment to serving as active, contributing citizens" (p. 12). Another ALS teacher recollected how the life skills trainings she conducted to her learners had become relevant to the needs of the community. Accordingly, the learners find themselves useful and felt accomplished. This was because they were able to extend services and skills during the barangay celebration.

After the trainings, some of my learners felt accomplished and useful, especially that our training was very timely; We had our training a few days before their Barangay Fiesta. My learners shared their acquired skills during the preparation of their barangay fiesta; So, while enhancing their gained skills, they also become useful in their community while volunteering.

Moreover, one ALS teacher described how her students have improved after they acquired the life skills from the class. The narratives portray those learners are now capacitated and able to demonstrate the same skills. The pictures below are pieces of evidence that these teachers 
transferred the skills they acquired from the series of training in ALS InFed project.

Before they don't know how to cook the right procedure to those kakanin, but now, they already knew it; They become familiar with the different materials used in cooking; then the good values, the right way on how to prepare foods; And now, they will know how to start a business.

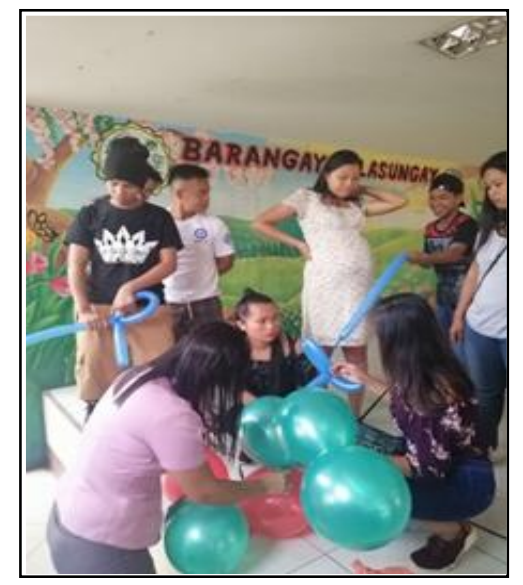

Figure 3: Baloon Art

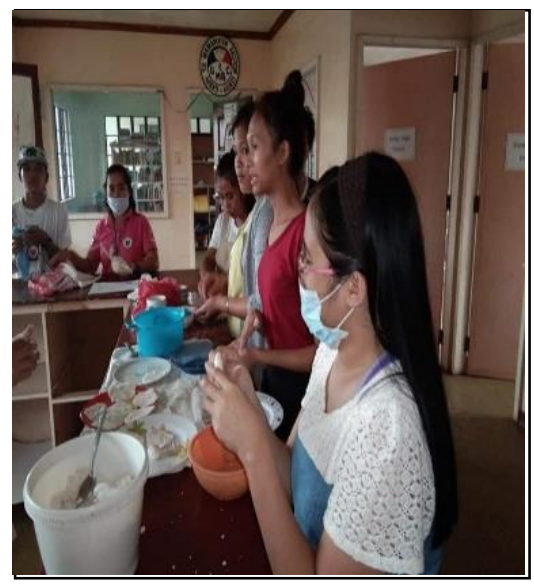

Figure 4: Lecture session

The transfer of skills among ALS teachers also happened within their families and communities. After being equipped through a series of training, their respective families have benefited from their life skills, especially during occasions and celebrations. Accordingly, they are no longer buying or ordering food for family celebration like birthdays. The participants are the ones who cooked or baked their food or pastries. Furthermore, they shared the skills not only to ALS learners and families, but also to their co-teachers, and friends. This gives us idea that skills are mastered once shared with anyone around you. For instance, some of them were saying:

I also shared the skills that I had with my co-teachers, friends, and family; Aside from my learners, my family, friends, and co-workers benefited from my acquired knowledge; After the series of trainings, I cook it myself when we celebrate within our family.

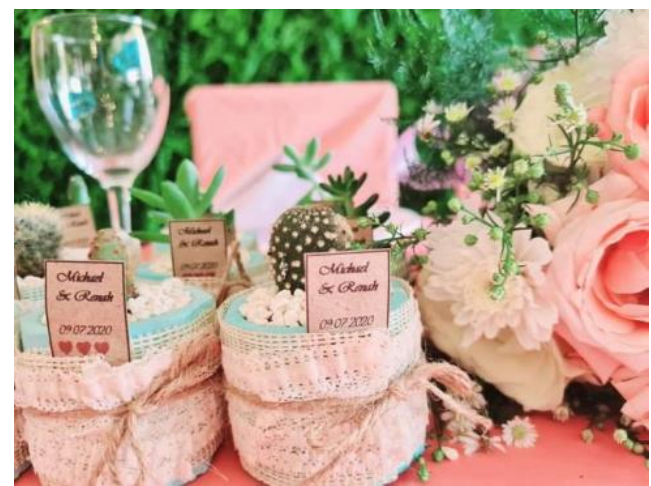

Figure 5: Output 1

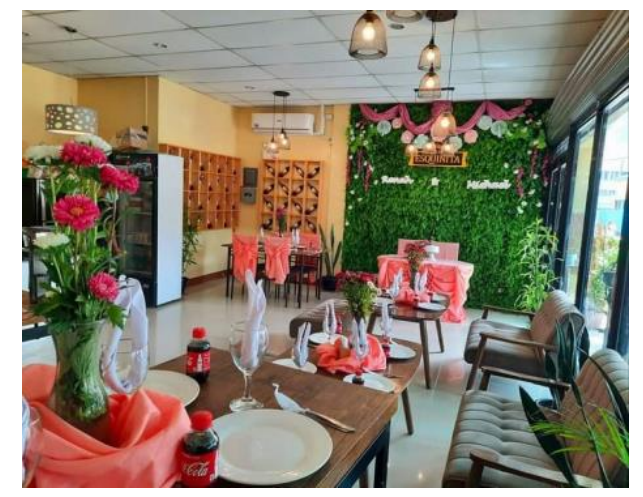

Figure 6: Output 2

This evaluation paper negated a previous study which reported that the majority of developing countries' life skills programs lack evaluation, monitoring and systematic implementation. Such review reported that programs are often conducted to yield short term results (Nasheeda et al., 2019). The photos below were outputs of an ALS InFed teacher who took advantage of the 
skills she developed in the training. Esquinita is a café where celebrations and occasions are held. Such ALS infeed teacher capitalized her skills on table management, decoration, and setting a venue for an intimate wedding. She serves as an on-call setter and decorator of the venue when there are occasions. This alone is the evidence that the life skills acquired by this teacher from the project were shared with the community. Thus, this has become a source of additional income. Having an additional income is a long-term opportunity for the teacher. During the Kaamulan Festival 2019 flower arrangement competition, some ALS InFed teachers participated in the said competition. Luckily, they were declared champion. This evidence suggests that the training has made a difference in the life skills of ALS InFed teachers. Before, they don't care about joining a competition. Now, they are more competent. Thus, the series of trainings has changed their lives progressively.

\section{Conclusion}

Implementers had done their best to achieve the objectives of the project. This study found evidence that the implementation of the ALS InFed project had satisfied the participants in all criteria. Thus, the series of training have met their expectations and had addressed their training needs. This paper concluded that the project was implemented effectively. Consequently, the ALS InFed teachers acquired life skills and shared them with learners, families, and community. Subsequently, ALS students had shared the same skills in their communities. Thus, this project has made an improvement on the life skills of ALS teachers and students. Certainly, the improvement goes beyond the Alternative Learning System classrooms, professional and personal lives of ALS InFed teachers since life skills have the potentials as sources of additional income.

\section{Acknowledgments}

The researchers are grateful to the participants for honestly giving their feedbacks and for participating in the virtual interview and for answering the open-ended questions. The officials of DepEd Malaybalay City deserved a recognition for their constant support to the Bukidnon State University.

\section{References}

Adolescent Girls Initiatives of World Bank. (2013). Life Skills: What are they, why do they matter, and how are they taught? Learning from Practice Series. AGI-World Bank.

Bukidnon State University. (2018). Extension Project: Capacitating Alternative Learning System Information Education Teaching in Teaching Life Skills. Bukidnon State University.

Cassidy, K. (2018). Preparation for Adulthood: A Teacher Inquiry Study for Facilitating Life Skills in Secondary Education in the United States. Journal of Educational Issues, 4(1), 33-46.

Commission on Higher Education. (2017). Commission Memorandum Order No. 83, s. 2017: Policies, Standards, and Guidelines for the Post Baccalaureate Diploma in Alternative Learning System. Commission on Higher Education.

D'Arcy, K. (2014). Literature Review: What do we know about life skills and leadership training for vulnerable children and young people? European Union.

Department of Education. (2019). Alternative Learning System-Education and Skills Training: Handbook for Implementers. DepEd.

Dupuy, K., Bezu, S., Knudsen, A., Halvorsen, S., Kwauk, C., Braga, A., \& Kim, H. (2018). Life 
skills in non-formal contexts for adolescent girls in developing countries: CMI 2018 Report. Chr. Michelsen Institute. https://bit.ly/3dWb7Ge

Nasheeda, A., Abdullah, H. B., Krauss, S. E., \& Ahmed, N. B. (2019). A narrative systematic review of life skills education: effectiveness, research gaps and priorities. International Journal of Adolescence and Youth, 24(3), 362-379. DOI: 10.1080/02673843.2018.1479278

Philippine News Agency. (2020). House OKs bill institutionalizing alternative learning system. PNA. https://www.pna.gov.ph/articles/1111916

Prajapati, R., Sharma, B., \& Sharma, D. (2017). Significance of Life Skills Education. Contemporary Issues in Education Research, 10(1), 1-6.

Riessman, C. K. (2008). Narrative methods for the human sciences. SAGE.

Shek, D. T. L., Lin, L., Ma, C. M. S., Yu, L., Leung, J. T. Y., Wu, F. K. Y., Leung, H., \& Dou, D. (2020). Perceptions of Adolescents, Teachers and Parents of Life Skills Education and Life Skills in High School. Applied Research in Quality of Life. Springer. DOI: https://doi.org/10.1007/s11482-020-09848-9

Sobel, D. (2004). Place-Based Education: Connection Classroom and Community. Nature and Listening. Antioch University New England.

Tan, S. (2018). Life Skills Education: Teachers'Perceptions in Primary School Classrooms in Finland and Singapore. A Thesis. University of Jyväskylä. Department of Education. https://bit.ly/3hWi0r3

Vihar, P. (n.d.). Life Skills Education. Central Board of Secondary Education.

World Bank. (2014). Strengthening Life Skills for Youth: A Practical Guide for Quality Programming. World Bank.

Yadav, S. B., \& Pingle, S. S. (2017). Development of Life Skills Programme and Study Its Effect on Life Skills Ability of Students. Indian Streams Research Journal, 7(2), 1-13.

\section{Copyrights}

Copyright for this article is retained by the author(s), with first publication rights granted to the journal. This is an open-access article distributed under the terms and conditions of the Creative Commons Attribution license (http://creativecommons.org/licenses/by/4.0/) 